\title{
The Genetics of Resistance to Gastrointestinal Parasites in Florida Native Sheep ${ }^{1}$
}

\author{
Zaira M. Estrada Reyes, Owen Rae, Carol Postley, and Raluca G. Mateescu²
}

Gastrointestinal infections are the main health problem for grazing sheep in the southern United States (US). The humid environmental conditions from this region are ideal for survival and growth of Haemonchus contortus, the most pathogenic gastrointestinal parasite. Infections with $H$. contortus are characterized by weight loss, anemia, reduced performance, and if untreated, death of susceptible individuals (Miller et al. 1998). In the US, anthelmintics have been used for the control of gastrointestinal nematodes of sheep for more than 30 years, with considerable development of anthelmintic-resistant populations being an unfortunate consequence. Alternative practices to control gastrointestinal nematode infections have been targeted to address anthelmintic resistance. One promising alternative approach is breeding for resistance to gastrointestinal nematode infections. Resistance to these infections is most likely based on inheritance of genes that are important in the expression of host immunity. Several breeds of sheep around the globe are known to be relatively resistant to gastrointestinal parasites. Using resistant sheep breeds exclusively or in crossbreeding programs could lead to improved resistance to nematode infection. The main benefits of using selection to enhance parasite resistance in sheep breeding programs are that genetic change is a permanent attribute of that animal, its performance is improved, and infectivity of pastures is decreased as a result of fecal egg reduction, leading to additional benefits for the susceptible and young sheep grazing in the same flock.
The Florida Native sheep, commonly known as Florida Cracker sheep, is one of the oldest breeds of sheep in North America. However, this heritage breed is now on the endangered list of sheep breeds. To ensure genetic diversity and long-term survival of the breed, protection of the current genetic stock is critical and conservation efforts are required to promote its breeding and production.

The Spanish introduced the sheep when they founded St. Augustine in 1565. It is believed that it was developed from Churro sheep. For almost 400 years, the sheep remained feral in the warm, humid environmental conditions of Florida until the open range era concluded at the end of 1945. Florida Native sheep are medium-sized. Live weight of mature ewes usually ranges from 100 to 125 pounds. Mature rams are 125 to 175 pounds. They have white to honey-red, medium-grade wool. The ewes can breed back one month after lambing, and they can produce up to two lambs per year.

This breed has demonstrated greater resistance to internal parasites than wool sheep and most other hair sheep breeds. The genetics underlying resistance to gastrointestinal nematodes in Florida Native sheep have been studied without identifying the genes or gene variants controlling variation, with selection based on phenotypic measures such as fecal egg count (FEC) and FAMACHA score. The FAMACHA® chart is based on the color of the conjunctival mucous

1. This document is AN361, one of a series of the Department of Animal Sciences, UF/IFAS Extension. Original publication date August 2020. Visit the EDIS website at https://edis.ifas.ufl.edu for the currently supported version of this publication.

2. Zaira M. Estrada Reyes, PhD, Department of Animal Sciences; Owen Rae, professor, Department of Large Animal Clinical Sciences, UF College of Veterinary Medicine; Carol Postley, owner, Fairmeadow Farm, Ocala, FL; and Raluca G. Mateescu, professor, Department of Animal Sciences; UF/IFAS Extension, Gainesville, FL 32611.

The Institute of Food and Agricultural Sciences (IFAS) is an Equal Opportunity Institution authorized to provide research, educational information and other services

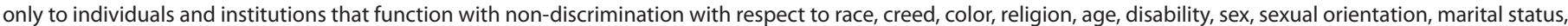

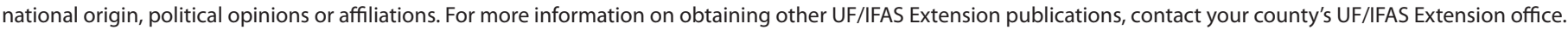
U.S. Department of Agriculture, UF/IFAS Extension Service, University of Florida, IFAS, Florida A \& M University Cooperative Extension Program, and Boards of County Commissioners Cooperating. Nick T. Place, dean for UF/IFAS Extension. 
membranes of animals. It changes from deep red (healthy individuals) to pink and white (highly anemic animals) shades. This tool has been used by sheep and goat producers from the southern US (Georgia, Louisiana, Florida, and Puerto Rico) as a valuable approach for identifying anemic individuals infected with $H$. contortus.

Identification of genetic variants in the sheep genome may help to identify a set of genetic markers significantly associated with parasite resistance in Florida Native sheep. Thus, the aim of a study conducted by the authors was to identify a set of potential genetic markers for resistance to gastrointestinal nematode infections for sustainable Florida Native sheep production with funding from Sustainable Agriculture Research and Education (SARE). A crucial aspect of this project was the participation of the 2018 president of the Meat Sheep Alliance of Florida, Carol Postley, and her Florida Native sheep flock. In the future, we expect to include more Florida Native sheep producers and continue the genetic evaluation of this heritage sheep breed.

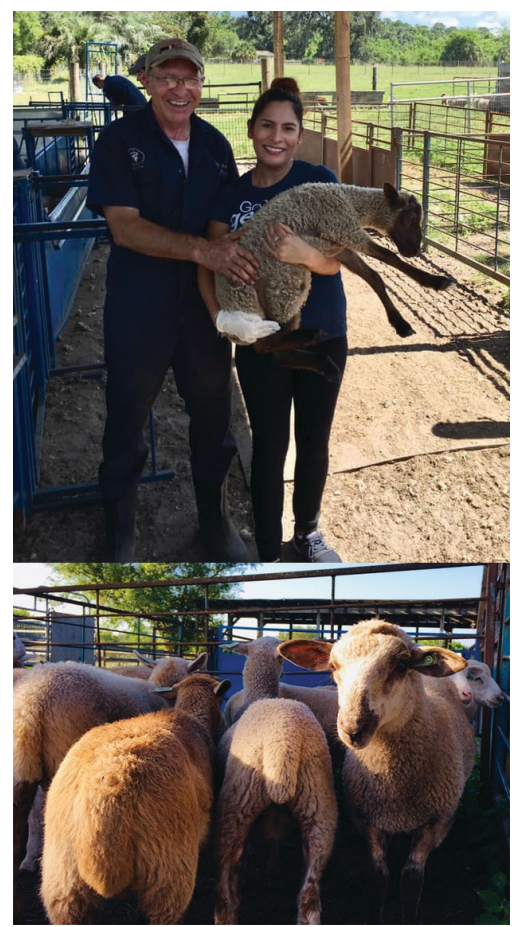

Figure 1. Florida Native sheep with researchers from the University of Florida: Owen Rae, professor, College of Veterinary Medicine; and Zaira Estrada Reyes, PhD, Department of Animal Sciences.

Credits: Zaira Estrada Reyes, UF/IFAS

All animals used in this study were from a commercial Florida Native sheep farm in Ocala, Florida (Figure 2). The selection flock was established in 1998 from an initial group of 80 rams ranked for $H$. contortus FEC, with high- and low-FEC rams mated with approximately 100 foundation dams. Since then, animals were selected for resistance to GIN solely on the basis of $H$. contortus FEC phenotyping and parentage recording. One hundred fifty-three female and male sheep were tested for gastrointestinal nematodes under natural grazing conditions. Animals were born between December 2017 and February 2018 and naturally exposed to parasites since birth. Phenotypic and pedigree information was used to construct the phenotype-pedigree database. To illustrate the phenotypic variation between resistant and susceptible animals in the study, a bar graph of fecal egg count determined at an initial assessment of the lambs (and deworming), at 10 days after the deworming, and at an assessment of lambs 38 days following deworming is presented below (Figure 3). All responded well to deworming, but two very clearly different populations of lambs were identified.

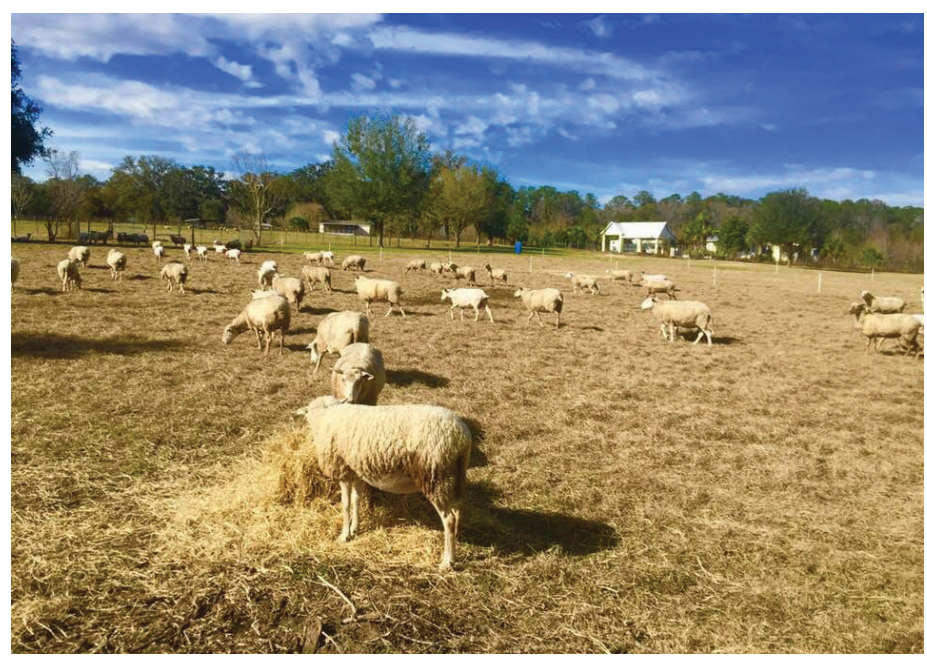

Figure 2. Florida Native sheep from Fairmeadow Sheep Farm. Credits: Zaira Estrada Reyes, UF/IFAS

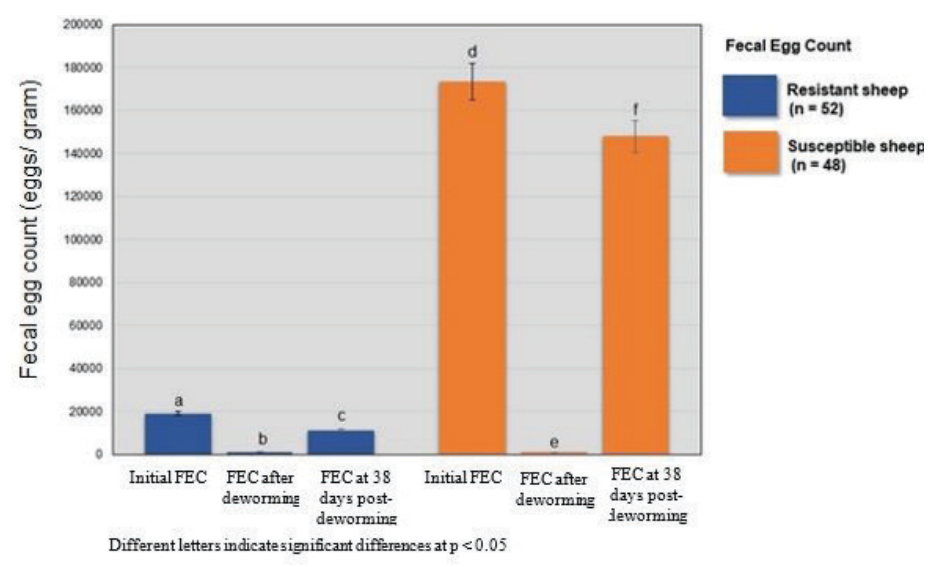

Figure 3. Fecal egg count performance between resistant and susceptible Florida Native sheep.

Credits: Zaira Estrada Reyes, UF/IFAS

Genotypes obtained from blood samples of these two populations of lambs were utilized to perform the identification of genetic variants associated with resistance. The total number of animals contributing to this project was 153 lambs, including female and male individuals. Genotypic data came from 100 lambs (52 characterized as resistant 
and 48 as susceptible) genotyped by targeted sequencing. Parasitological and hematological traits were evaluated and a total of 23 genomic regions covering 13 genes were associated with fecal egg count, FAMACHA score, average daily gain, red blood cell count, hemoglobin level, white blood cell count, neutrophil count, basophil count, and eosinophil count. The results from this study revealed candidate genetic variants for genes involved in the immune response to $H$. contortus exposure and provided additional marker information that has potential to aid selection of resistance to gastrointestinal parasites in Florida Native sheep. Improvement of Florida Native sheep selection for resistance to gastrointestinal nematode infections is the long-term goal of the authors. Future research is expected to provide an insight into the potential genetic markers for resistance to gastrointestinal nematode infections. We will continue to increase the size of the phenotypic, pedigree, and genotypic database for Florida Native sheep and validate our findings using genome-wide scans. The end result is intended to assist Florida Native sheep producers in managing this very important production-limiting condition in their flocks. 